\title{
SAINS, TEKNOLOGI DAN PENDIDIKAN
}

\author{
Oleh: Suswandari *)
}

\section{Abstrak}

Sains teknologi dan pendidikan merupakan bagian integral yang tak terpisahkan dalam pembentukan karakter bangsa. Dalam upaya pembelajaran Sain dan teknologi tidak bisa dipisahkan dari konteks mulai dari hal budaya masyarakat lokal, regional, nasional dan internasional. Misi utama pendidikan sains dan teknologi adalah membentuk peserta didik yang melek sains dan teknologi dalam berfikir global dan bertindak lokal.

Kata kunci: sains, teknologi dan pendidikan

\section{PENDAHULUAN}

Para pengamat pendidikan tidak sedikit yang mengungkapkan bahwa pendidikan rnerupakan investasi jangka panjang bagi eksistensi suatu bangsa, Hal ini berkaitan dengan adanya keyakinan bahwa apa yang akan terjadi pada masa mendatang, tidaK dapat dilepaskan dari apa yang diiakukan pada saat ini me!a!ui suatu proses pendidikan. Dengan demikian pendidikan yang diiaksanakan harus mampu meiahirkan peserta didik yang siap dalam menghadapi tantangan yang ada, baik masa sekarang ataupun yang akan datang.

Disadari atau tidak, bahwa situasi dunla saat ini sedang dan terus berlangsung pergeseran dinamika kehidupan urnat manusia yang dipercepat oleh kemajuan sains dan tekhnologi. Menjamurnya media informasi, peralatan transportasi dan iain sebagainya mempunyai peran besar dalam gerak perubahan sikap hidup manusia. Hai ini seperti diungkapkan Lewis Mumford seperti yang dikutip To Thi Anh ( 1985) berikut ini.
... jelas membuktikan perubahan radikal pada seluruh manusia, sebagai akibat pengaruh sains dan tekhnologi, Peralihan dari teknik ernpiris yang terikat tradisi menuju cara eksparimental telah membuka kemungkinan bagi energi nuklir, transportasi supersonik, intelegensi kibernetik, dan komunikasi jarak jauh. Sejak jaman piramida tak pernah dialarni perubahan fisik yang demikian cepat dalam jangka waktu yang begitu singkat, Sernua perubahan ini menimbulkan pula perubahan dalam kepribadian manusia.

Bila dicerrnati dengan sungguh-sungguh, efek dari berbagai perkembangan sains dan teknologi telah meningkatkan interaksi antar manusia. Munusia termanjakan oleh berbagai kemudahan karena adanya temuan-temuan baru perangkat hldup yanq lebih baik. Akibat lebih jauh, juga muncul cakrawala intelektual masyarakat yang semakin meluas, arus keterbukaan dan demokratisasi yang sernakin terasa.

*) Suswandari adalah dosen pada FKIP Unioversitas Muhammadiyah Prof. DR. HAMKA, Jakarta 
Perkembangan sains dan tekhnologi cenderung terus mempengaruhi segenap kehidupan manusia. Gejaia ini sernakin rnudah diternukan dalarn kehidupan masyarakat dewasa ini. Masyarakat sernakin sadar dan menghargai berbagai informasi untuk mengejar ketertinggalannya. Berbagai ketertinggalan yang dialami oleh sebagian masyarakat justru akan melahirkan ketegangan (tension) dalam berbagai aspek kehidupannya. Adanya keteganganketegangan inilah yang akan menuntut seseorang, keiuarga, masyarakat dan bangsa untuk melakukan adaption dan adjusment yang cepat dan cara yang cerdas. Hai ini dapat ditempuh meialui aktivitas pendidikan.

Dunia pendidikan adalah dunia yang strategis untuk berbagai kepentingan. Sehubugan dengan hal tersebut, rnasih sangat pantas bila pendidikan lah yang dapat dijadikan sebagai salah satu wahana sosialisasi aplikasi sains dan tekhnologi yang terus berkernbang. Hal inl seiring dengan rumusan tujuan pendidikan nasionai yang menjelaskan bahwa: Pendidikan bertujuan membentuk dan rneningkatkan kualitas manusia Indonesia yang beriman dan bertaqwa terhadap Tuhan Yang Maha Esa, berbudi pekerti luhur, berkepribadian, berdisiplin, bekerja keras, tangguh, bertanggung jawab, mandiri, cerdas, , , , rnemilikii pengetahuan ... dan trampil . . mempertebal semangat kebangsaan calon rasa kesetiakawanan sosia! . . . ( Y. B. Mangun Wljaya, 1998).

Dengan demikian dapat ditarik suatu benang merah bahwa pendidikan diyakini dapat memberikan sumbangan positif bagi manusia dalam menemukan dunia dan masyarakat yang lebih adil serta rnenjunjung etika hidup bersama yang positlf dengan suasana harmonJs dalam dunia yang disebut dengan globall village.

Berkenaan dengan uraian di atas, tulisan sederhana ini rnencoba untuk menelaah lebih jauh tentang keberadaan sains, tekhnologi dan tujuan pendidikan, sebagai salah satu renungan dalam upaya meminimalisir meluasnya efek negatif dari perluasan sains dan tekhnologi itu sendiri. Untuk memperrnudah pemahaman, maka dalarn ulasan ini akan dimulai dengan mengupas tentang konsep sains dan tekhnologi, yang dilanjutkan dengan pembahasan tentang berbagal kecenderungan dalam dunia pendidikan kaitannya dengan perkembangan sains dan teknologi. Tulisan ini diakhiri mernbahas relevansi sains dan tekhnologi dengan tujuan pendidikan dan penutup. Tulisan ini menjawab tentang dua hal yaitu: 1. Bagaimana kaitan sains tekonologi dan pendidikan, 2. Bagaimana misi pendidikan sains dan teknologi.

\section{SAINS, TEKNOLOGI DAN PENDIDIKAN}

\section{A. Sains}

Dalarn pandangan Hungerfold, Volk dan Ramsey (1990) dikatakan bahwa pengertian sains mencakup tiga aspek, yaitu :

1. Proses memperoleh informasi melalui metode empiris (empirical method)

2. Informasi yang diperoleh rnelaiul penyelidikan yang telah ditata secara logis dan sistematis.

3. Suatu kombinaasi proses berpikir kritis yang menghasilkaan informasi yang dapat dipercaya dan valid.

Mencermati tiga aspek sains di atas dapat dikatakan bahwa sains, sesungguhnya rnempunyai dua elemen utama, yaitu proses dan produk yang akan saiing mengisi daiam derap kemajuan dan perkembangan sains itu sendiri. Dalam hasi! penelitian La Maronta Gallb ( 2002 \}, dinyatakan bahwa: “... sains sebagai suatu proses merupakan rangkaian kegiatan ilmiah atau hasii observasi terhadap fenomena alam untuk menghasiikan scientific knowledge yang lazim disebut denga produk sains", Adapun produk sains dapat meliputi fakta, konsep, prinsip, generalisasi, teori dan hukum serta model yang dapat dinyatakan dalam berbagai cara.

Lebin dan itu, Tfowbudge dan Bybee seperti dikutip La Maronta galib (2002) menjelaskan bahwa sains merupakan 
representasi dari suatu hubungan dinamis yang mencakup tiga faktor utarna, yaitu : the extant body scientific knowledge, the values of science, the methods and processes of science. Dalam konsep ini, pandangan sains sudah semakin meluas. Karena dengan tegas dinyatakan bahwa sains tidak hanya berkaitan dengan proses dan rnetode ataupun produk saja. Namun demikian sains sudah diiihat pada posisi aspek values atau niiai-nilai.

Sains dilihat sebagai sekumpulan nilainilai dan prinsip yang dapat menjadi petunjuk dalam pengembangannya. Hal ini dapat meliputi cara berpikir, sikap dan langkah-langkah kegiatan sains positif dalam rangka memperoleh produk sains yang bermanfaat dalam kehidupan manusia. Dalam konteks ini kedudukan sains semakin melebar, karena tidak dibatasi pada aktivitas cara bekerja, cara melihat dan cara berpikir saja. Melainkan telah pada posisi science as a way of knowing. Artinya sains sebagai proses dapat meliputi kecenderungan, sikap tindakan, keingintahuan, kebiasaan berpikir dan seperangkat prosedur. Dengan kata lain, nilai-nilai sains akan berhubungan dengan tanggung jawab moral, niiai sosial, keingintahuan, kejujuran, ketelitian, Ketekunan, hati-hati, toleran, efisien dalam pengambilan keputusan dan sebagainya. (Sofian Efendi, 1997).

\section{B. Tekhnologi}

Everett M. Rogers (1995) menjelaskan bahwa : "technology is a design for Instrumental action that reduces the uncertainty in the cause effect relationship involved in achieving a dessired out conms". Sementara itu, Fisher (1997) seperti yang dikutip La Maronta Galib ( 2002 ) mengatakan bila tekhno!ogi merupakan keseluruhan upaya yang dilakukan oleh masyarakat untuk mengadakan benda-benda agar memperoleh kenyamanan. Dalarn pengertian yang lain, tekhnologi merupakan studi tentang man made world. Hal ini diartikan bahwa tekhno!ogi berhubungan dengan kreasi atau perekayasaan alam (Jalaluddin Rahmat, 1999) dan solusi dari dan untuk manusia dalam menghadapi masalah dan tantangannya.

Terdapat pendapat lain yang menjelaskan bahwa tekhnologi merupakan craft by machines and skilled process (Everett M. Rogers, 1995). Artlnya tekhnologi sebagai keahlian (craft) yang akan melibatkan ketrampiian fisik dan membuahkan hasil yang bermanfaat untuk pemecahan masalah yang dihadapi manusia. Sernentara itu, tekhnoiogi sebagai keterampilan pasti memerlukan pemikiran kreatif dan memiliki nilai-nilai yang bermanfaat bagi manusia. Dengan kata lain, pada dasarnya tekhnologi merupakan pengunaan pengetahuan dan ketrampilan secara kreatlf untuk memecahkan rnasalah sosial atau pribadi dan didesain dalarn rangka pelayanan masyarakat.

\section{Pendidikan}

Pendldikan istilah yang tidak asing lagi dalam kosa kata masyarakat. Sebagian besar pengamat sepakat bahwa tujuan mendasar dari suatu proses pendidikan adalah pengembangan potensi yang ada dalam diri manusia seluas-seluasnya untuk dapat membuka tabir rahasia alam secara iengkap, Hal ini dapat diartikan bahwa aktivitas pendidikan tidaklah cukup bila hanya rnengedepankan aspek kognitif inforrnatif saja. Melainkan, harus dilengkapi dengan pengembangan aspek afektif yang berhubungan dengan moral, spiritual, budaya dan penalaran sosialnya. Dengan kata lain, pendidikan menjadi suatu proses yang bersifat personalistik (Edward. B. Fiske, 1998), yaitu isi proses tersebut mencakup sosiaiisasi nilai, kepribadian dan martabat manusia.

Seluruh lapisan masyarakat mempunyai keinginan yanq seragarn, bahwa dengan mengikuti proses pendidikan akan diperoleh pengetahuan dan ketrampilan yanq dapat dimanfaatkan dalam rnengatasi berbagai persoalan kehidupan. Budi pekerti luhur, kepribadian 
yang jelas, disipiin. semangat kerja keras, tangguh, tanggung jawab, mandiri, cerdas, inovatif dan kreatif, demokratis, setiakawan dan sebagainya merupakan setumpuk harapan dari suatu proses pendidikan yang diiaksanakan.

Berkenaan dengan semakin meningkatnya tantangan dan masalah sebagai perpanjangan dari perkernbangan sains dan tekhnologi, pendidikan nasiona! tetap memiliki peran yang sanqat strategis. Berbeda dengan peran pendidikan dl negara-negara maju, yang terus menekankan pada aspek transfer of knowledge, tidak demikian dalam peran pendidikan nasional kita. Pendidikan nasional memiliki beban yang berat (Azyumardi Azra, 2000) untuk dapat merealisasikan tujuan yang telah ditetapkan. Pendidikan nasional berperan bukan hanya sebagai sarana transfer iimu, tetapi mencakup proses pembudayaan (enkulturasi\} nilai yang sangat luas cakupannya, kaitannya dengan pembentukan karakter dan watak bangsa.

\section{DUNIA PENDIIDIIKAN KAITANNYA DENGAN PERKEMBANGAN SAINS DAN TEKNOLOGI}

Proses pendidikan yang terencana dapat menjadi sarana sosialisasi dan kulturalisasi nilai-nilai sosial budaya nasional sebagai salah satu faktor dominan dalam pembangunan bangsa. Pendidikan berperan dalam mempersiapkan anak bangsa, baik secara Individual maupun sosial, agar rnereka memiliki kemampuan, keterampilan, etos dan rnotivasi untuk berpartisipasi dalam aktualisasi dan institusionalisasi masyarakat madani, seperti telah terumuskan dalam tujuan pendidikan nasionai.

Seiring dengan pesatnya perkernbangan tekhnologi dan sains dirasakan adanya beberapa kecenderungan baru dalam dunia pendidikan. Adapun kecenderungan tersebut antara lain seperti berikut :
1. bergesernya paradigma pendidikan dari sistem yang berorientasi pada guru ke pembelajaran yang berorientasi pada sisvva,

2. makin memasyarakatnya pendidikan jarak jauh sebagai sistem pendidikan alternatif,

3. makin banyaknya pilihan sumber belajar yang tersedia serta mudahnya memperoleh berbagai inforrnasi,

4. makin diperlukannya standar kualitas global dalam rangka persaingan.

Berbagai kecenderungan tersebut secara perlahan namun pasti sangat mempengaruhi dunia pendidikan kita. Oleh karena itu besar kecilnya pendayagunaan tekhnologi dan sains dalam pendidikan dan pernbeiajaran akan mempengaruhi seberapa cepat kecenderungan tersebut terwujud dalam dunia pendidikan kita.

Penerapan sains dan tekhnologi dalam dunia pendidikan memiliki dua tujuan. Pertama, untuk kegiatan proses pembelajaran. Kedua untuk rnenunjang kegiatan administratif, yaitu pengelolaan sistem pendidikan yang bersangkutan.

Sains dan tekhnologi berkembang cepat baik dan segi jumlah, tingkat kerumitan dan kemampuannya. Media pendidikan sebagai produk sains dan tekhnologi juga semakin bervariasi. Berbagai pilihan tekhnologi dan sains untuk pengembangan pendidikan antara lain: tekhnologi audio, audio dan data, video, computer, surat eiektronik, voice mail, internet dan sebagainya.

Devvasa ini hasil sains dari tekhnoiogi teiah rnemasuki sernua aspek kehidupan termasuk pendidikan. Oleh karena itu, daiam rnemanfaatkan sains dan teknoiogi guna rnendukung tujuan pendidikan harus diciptakan sarana, prasarana, dan nuansa pembelajaran yang seirama. Setiap individu yang dibelajarkan harus dibekali dengan semangat nilai sains dan teknoiogi yang sesungguhnya. Sains dan teknoiogi harus ditempatkan daiam konteks sosial budaya masyarakat umum, bersama-sama dengan nilai budaya lokal, kebiasaan, tradisi serta berfokus pada isyu atau masalah yang sedang dihadapi masyarakat. Karena 
disadari betul bahwa berkembangnya sains dan tekhnologi di sarnping rnemiliki berbagai keunggulan juga memiliki berbagai kelemahan. Hal ini seperti diungkapkan oleh To Thi Anh tentang Kecemasannya terhadap perkembangan sains dan tekhnologi yang sangat cepat seperti berikut.

Setiap kali tekhnologi yang kita ciptakan nampaknya mau menjerumuskan dan menghanguskan kita sendiri, kekuatan klta menjadi tak berdaya .... Kendaraankendaraan makin bertambah, melumpuhkan jalan raya yang ada. . . . Kita terpukul karena sekolah tidak lagi mendidik, kebudayaan tidak lagi membudayakan orang.... Pada setiap puncak kemajuan yang kita capai, udara menjadi kotor, pantai ternoda, mata air dan sungai berhenti mengalir, tetumbuhan hijau mengering, burungburung terbang menjauh dan sampah kian menimbun ...
Kekhawatiran terhadap pesatnya perkembangan sains dan tekhnologi memang diakui banyak orang. Artinya hasil dan pemanfaatan sains dan tekhnologi dapat menimbulkan berbagai perrnasalahan baru dalam kehidupan manusia. Pemikiran ini sesuai dengan apa yang direnungkan Erich Fromm dalam kutipan To Thi Anh berikut ( 1985):

. . masyarakat yang semata-mata dikuasai mesin diarahkan untuk mendapatkan hasil sebanyak mungkin dan lalu menggunakannya, diatur oleh komputer dan dalam proses ini manusia hanya menjadi satu bagian dari mesin itu



Gambar 1. Interaksi Sains - Teknologi - Masyarakat

Menjadi hal sangat berbahaya bila sains dan tekhnologi berjalan tanpa dijiwai semangat humanis. Karena proses utama tekhnologi mempunyai kecenderungan mematikan alam, masyarakat dan pribadi manusia. Alarn diperkosa, hutan digunduli, sungai, pantai, pelabuhan dikotori. Masyarakat dirusak oleh persaingan yang kejam, perpecahan dalam keluarga, tradisi dan iman. Oleh karena itu, di sini lah pendidikan memegang posisi sentral dalam mensosialisasikan berbagai hasli sains dan tekhnologi secara adil dan seimbang.
Menjadi semakin jelas, bahwa antara sains, tekhnologi dan pendidikan merupakan tiga komponen dasar perubahan peradaban yang harus dikembangkan secara terintegrasi. Keterkaitan antara sains, tekhnologi dan pendidikan dalam kehidupan masyarakat dapat dicermati dalarn gambar 1 .

Gambar tersebut rnenunjukkan adanya sirnbiosis yang tidak terlepaskan. Artinya tekhnologi memerlukan sains untuk rnenghasilkan model sarana prasarana kehidupan yang baru, dan diteruskan melalui 


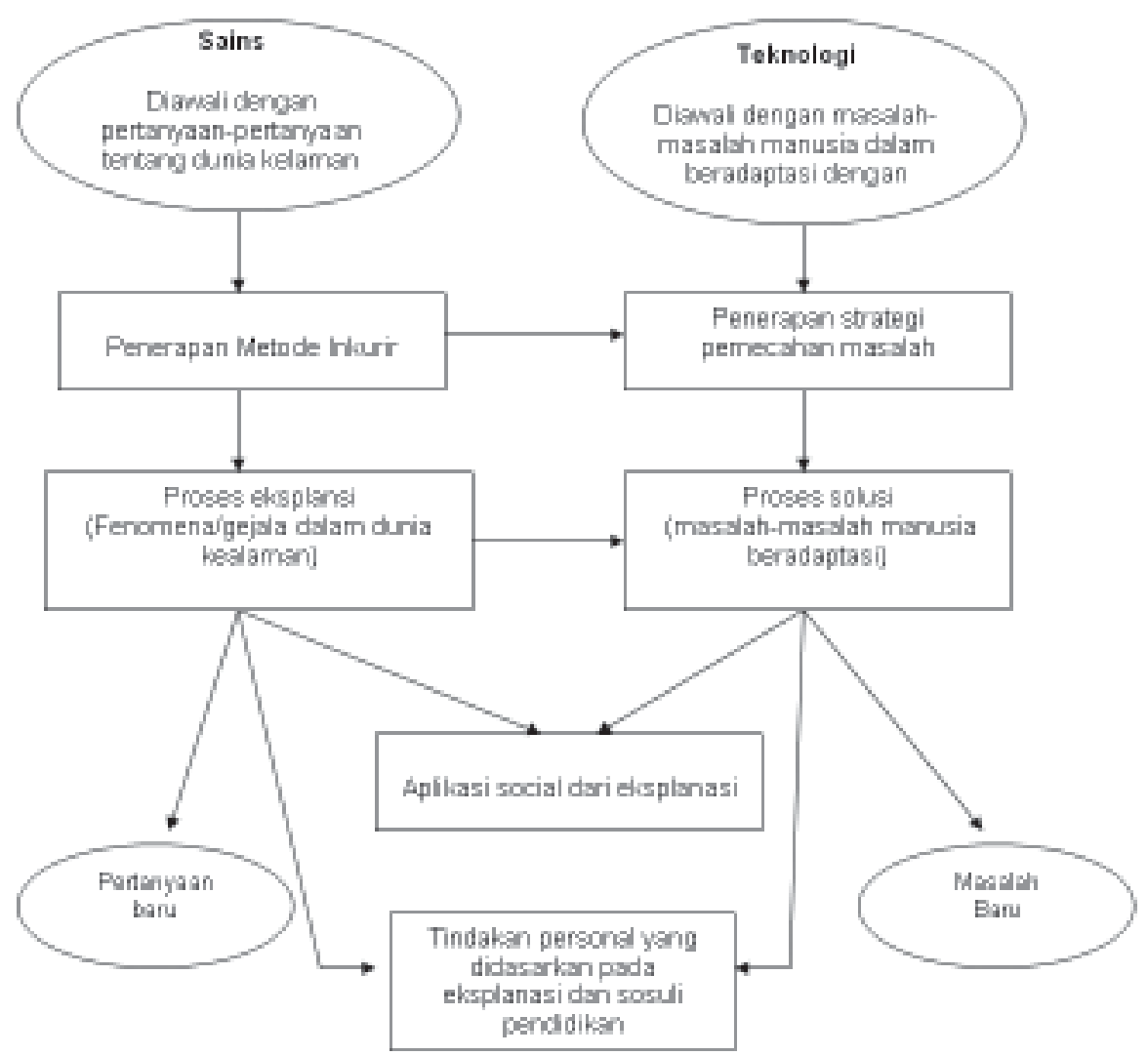

Garnbar 2.

Hubungan antara sains, tekhnologi dengan tujuan pendidikan

proses pendidikan dalam rangka pemanfaatannya oleh masyarakat. Pengenalan sains dan tekhnoiogi melalui dunia pendidikan berhubungan dengan masalah mempeiajari kognisi atau konsep, ketrampilan proses, sikap, kreativitas dan aplikasi.

Nampaknya bahwa sains dan tekhnoiogi rnempunyai titik niiai yang berbeda. Kegiatan sains diawali dengan bertanya kepada alarn. Sedangkan tekhnologi diawali dengan masalah yang sedang dihadapi manusia dalam beradaptasi dengam lingkungan alam. Keduanya berinteraksi pada penerapan rnetode inkuiri dan pernecahan masalah, Hasil-hasil eksplanasi memunculkan pertanyaan baru yang perlu dljawab kembali. Sementara solusi pemecahan masalah juga melahirkan masalah baru yang juga perlu dipecahkan lagi, demikian seterusnya. Sementara titik temu yang mempertalikan keduanya dengan tujuan pendidikan adalah pada apiikasi sosia! dan eksplanasi penomena alam dan solusi masalah rnanusla dalarn beradaptasi dengan lingkungan. Dengan demikian pertalian antara sains, tekhnologj dan tujuan pendidikan terietak pada nilai-nilai dan manfaat atau penerapan sains dan tekhnologi bagi kehidupan rnanusia.

\section{PENUTUP}

Dari pembahasan di atas dapat disimpulkan bahwa:

1. Sains, teknologi dan pendidikan rnenjadi satu bagian integral dalam suatu proses pembentukan karakter bangsa. Dengan demikian dalam upaya pembeiajaran sains dan teknologi tersebut tidak dapat dipisahkan dari konteks nilai sosial budaya masyarakat lokal, regional, nasional dan internasional.

2. Misi utama pendidikan sains dan tekhnologi adalah membentuk peserta didik sebagai warga negara yang melek 
sains dan teknologi dalam berpikir global dan bertindak lokal.

\section{DAFTAR PUSTAKA}

A. Malik Fadjar. (1999). Platform Reformasi Pendidikan dan Pengembangan Sumber Daya Manusia. Jakarta : Ditjen Binbaga Islam Depag R.I

Azyumardi Azra. (2000). "Reposisi dan Rekontruksi Pendidikan Nasional Menuju Pembangunan Masyarakat Madani". Makalah Seminar, Universitas Negeri Yogyakarta.

Edward B. Fiske. (1998). Decentralization of Education Politic and Consensus. United States of America.

Evert M. Rogers. (1995). Diffusion of Innovation. New York : 886 Third Evenue

Hungerford, H.R. Volk, T.L. Ramsey, J.M. (1990) Science technology society: Investigating and
Evaluating STS Issues and Solution. Illionis : STIPES Publishing Co.

Jalaiuddin Rahmat. (1999). Rekayasa Sosiai. Bandung: Rosda Karya.

La Maronta Galib. ( 2002 ). "Pendekatan Sains Teknologi Masyarakat dalarn Pembeiajaran Sains di Sekolah". Jurnal Pendidikan dan Kebudayaan. Tahun Ke-8. No. 034. Jakarta: Balitbang Depdiknas.

Sofian Efendi. (1997). "Kebangkitan RRC Revitalisasi Pembangunan Nasiona! Melalui Pendidikan, Iptek dan Desentralisasi". Republika, Selasa. 17 November,

To Thi Anh, (1985). "Eastern and Western Cultural Values". Alih Bahasa: John Yap Pareira. Nilai Budaya Timur dan Barat Konflik atau Harmoni. Jakarta; Gramedia.

Y.B. Mangun Wijaya. ( 1998 )." Mencari Visi Dasar Pendidikan". Yogyakarta: Basis. No, 01-02 Tahun ke 47 Januari- Februari.

\section{RALAT}

Kami informasikan bahwa telah terjadi kekeliruan pada salah satu rtikel Jurnal Teknodik Vol. 12 N0.1 edisi Juni 2008. Oleh karena itu, bagi siapa saja yang telah membaca atau menggunakan/ mengutip sebagian atau keseluruhan dari artikel itu, mohon untuk memperhatikan ralat sebagai berikut:

1. Artikel berjudul: "Penerapan Model Pembelajaran Interaktif pada Mata Pelajaran IPA di SD" ini adalah karya Dra. Prayekti, M.Pd. (Dosen Fakultas Keguruan dan Ilmu Pendidikan, Universitas Terbuka).

2. Karena kesalahan teknis oleh editor Jurnal Teknodik Vol. 12 No. 1 Juni 2008, telah terjadi kekeliruan artikel dan pencantuman nama penulis yang seharusnya Dra. Prayekti M.Pd. (Dosen Fakultas Keguruan dan Ilmu Pendidikan, Universitas Terbuka) menjadi Dra. Suprayetkti, M.Pd. (Dosen Prodi. Teknologi Pendidikan, FIP, UNJ)

3. Kekeliruan penulisan nama dan artikel yang dimuat semata-mata disebabkan oleh kesalahan teknis yang dilakukan oleh editor Jurnal Teknodik Pustekkom tersebut, bukan karena terjadi plagiarisme oleh Dra. Suprayetkti, M.Pd.

4. Karena Dra. Prayekti, M.Pd. tidak pernah mengirim artikel untuk Jurnal Teknodik, dan artikel tersebut sebenarnya telah terbit di Jurnal Pendidikan dan Kebudayaan No. 060, tahun ke12, Mei 2006, serta kemunculannya di website ini dan di Jurnal Teknodik Vol. 12 No. 1 Juni 2008 adalah semata-mata dikarenakan kesalahan teknis seperti tersebut di atas, maka artikel tersebut dinyatakan diralat dan tidak dianggap ada (tidak berlaku) untuk Jurnal Teknodik tersebut.

5. Untuk selanjutnya, jika Anda telah membaca dan menggunakan atau mengutip sebagian dan atau keseluruhan dari artikel tersebut, agar mencantumkan nama author/penulis: Dra. Prayekti, M.Pd. (Dosen Fisika Fakultas Keguruan dan Ilmu Pendidikan, Universitas Terbuka), Jurnal Pendidikan dan Kebudayaan No. 060, tahun ke-12, Mei 2006 bukan Dra. Suprayetkti, M.Pd. seperti tercantum dalam Jurnal Teknodik ini.

6. Klarifikasi ini dilakukan atas permintaan sendiri dari penulis (Dra. Prayekti, M.Pd.) 